\title{
Atendimento inicial às queimaduras de mão: revisão da literatura
}

\author{
Initial assistance to hand burns: literature review \\ Jefferson Braga Silva $₫$, Márcio Pereira Lima Ferdinandoํㄹ , João Guilherme Meinem Garbin ${ }^{3}$, \\ Victoria d'Azevedo Silveira ${ }^{3}$
}

${ }^{1}$ PhD. Livre Docente em Cirurgia da Mão pela Universidade Federal de São Paulo (UNIFESP). Chefe do Serviço de Cirurgia da Mão e Microcirurgia Reconstrutiva do Hospital São Lucas da Pontifícia Universidade Católica do Rio Grande do Sul (PUCRS). Diretor da Faculdade de Medicina da PUCRS. Ex-Presidente da Sociedade Brasileira da Cirurgia da Mão. Ex-Presidente da Sociedade Brasileira de Microcirurgia. Porto Alegre, RS.

${ }^{2}$ MD. Pós-Graduação em Cirurgia Geral PUCRS. Médico residente do Serviço de Cirurgia da Mão e Microcirurgia Reconstrutiva da PUCRS. Porto Alegre, RS

${ }^{3}$ Acadêmicos da Faculdade de Medicina da PUCRS. Porto Alegre, RS.

\section{RESUMO}

Objetivos: Abordar, por meio de uma revisão da literatura, o manejo das queimaduras de mão, com ênfase nos cuidados iniciais.

Métodos: No período entre fevereiro e julho de 2015, foram revisados 30 artigos selecionados nas bases de dados MedLine/PubMed, LILACS, SciELO e Google Acadêmico, inclusos tanto os de língua inglesa quanto portuguesa, publicados nos últimos 10 anos e que correspondessem aos seguintes descritores: queimadura de mão; ferimento de mão; tratamento agudo; tratamento primário; e seus correspondentes em inglês.

Resultados: É apresentada a classificação das queimaduras conforme a profundidade, extensão e fatores agravantes. São abordadas as condutas iniciais que evitam complicações como mão em garra, síndrome compartimental e infecções. Os procedimentos iniciais incluem curativos oclusivos, escarotomia, fasciotomia, abertura do túnel do carpo, seguidos por curativos com agentes antimicrobianos tópicos, desbridamento e enxertos. São discutidos aspectos controversos sobre o momento mais indicado para a intervenção cirúrgica, caso esta seja necessária.

Conclusões: A correta abordagem inicial da queimadura de mão poderá evitar sequelas irreversíveis. O manejo adequado na queimadura de mão inclui desde a avaliação clinica inicial da área queimada por um médico generalista à realização de condutas precoces com o objetivo de evitar a perda de função do membro e futuras reconstruções desnecessárias. A elevada incidência desse tipo de queimadura também acentua a relevância de uma conduta adequada.

DESCRITORES: mãos; ferimentos e lesões; queimaduras; tratamento primário.

\section{ABSTRACT}

Aims: To address, through a literature review, the management of hand burns, with emphasis on the initial care.

Methods: Between February and July 2015, 30 articles selected in the databases Medline/PubMed, LILACS, SciELO and Google Scholar were reviewed. Both the English and Portuguese languages were included in the search. Selected articles were published in the last 10 years and matched the following descriptors: hand burn; hand injury; acute treatment; primary treatment; and their counterparts in Portuguese.

Results: Classification of burns is displayed, including depth, extent and aggravating factors. The initial management that avoid complications such as claw hand, compartment syndrome and infection is addressed. Early procedures include occlusive dressings, escharotomy, fasciotomy, and carpal tunnel opening, followed by dressings with topical antimicrobial agents, debridement and grafting. Controversial aspects are discussed on the most appropriate time for surgical intervention, if it is necessary.

Conclusions: The correct early approach to hand burns can prevent irreversible consequences. The appropriate management on hand burns includes since the initial clinical evaluation of the burned area by a general practitioner, to the realization of early procedures in order to prevent limb function loss and unnecessary future reconstructions. The high incidence of this type of burn also stresses the importance of a proper conduct.

KEY WORDS: hands; wounds and injuries; burns; primary treatment. 


\section{INTRODUÇÃO}

A incidência frequente de queimaduras de mão e suas possíveis sequelas funcionais conferem grande importância ao conhecimento sobre a avaliação clínica e o tratamento primário desses traumas [1]. Segundo Kamolz et al. [2], as queimaduras que envolvem a mão estão presentes em mais de $80 \%$ de todos os casos registrados de queimaduras. Elas são mais comumente vistas em crianças e homens da classe trabalhadora, sendo assim fundamental a reabilitação das funções e da aparência desse membro, com objetivo de reinserção profissional e social do paciente na sociedade [1-4].

As mãos representam apenas $6 \%$ da superfície corporal, porém podem comprometer $57 \%$ da funcionalidade de uma pessoa e, por essa razão, a queimadura de mão pode gerar um grande impacto na vida do paciente. Um atendimento adequado na fase inicial da lesão determinará o resultado final do tratamento. Após esse primeiro atendimento, o paciente deve ser avaliado por uma equipe multidisciplinar, garantindo uma melhor sobrevida estética, funcional e psicológica. Portanto, devido à alta incidência de queimaduras de mãos e ao impacto dessas lesões na qualidade de vida dos pacientes, destaca-se a importância da constante atualização sobre este tema [5].

\section{MÉTODOS}

O presente artigo constitui-se em uma revisão de literatura realizada entre fevereiro e julho de 2015 . Elegeram-se como critérios para inclusão dos estudos a publicação nos últimos 10 anos e os descritores queimadura de mão, ferimento de mão, tratamento agudo e tratamento primário (e seus correspondentes em inglês). Para a revisão foram consultadas as bases de dados MedLine/PubMed, Scielo e Google Acadêmico.

\section{RESULTADOS DA SELEÇÃO}

Os artigos foram selecionados de acordo com o grau de relevância para a proposta desta revisão e foram incluídos trabalhos originais e de revisão. Foram selecionados para este estudo 30 artigos científicos a partir de um conjunto de 44 que estavam disponíveis a partir dos descritores utilizados, sendo excluídos artigos anteriores a 2006 e que não correspondessem a tratamento primário, tratamento agudo ferimento de mão, ou queimadura de mão.

\section{CONTEÚDO DA REVISÃO}

\section{Conceito e origem do trauma}

Uma lesão do tecido orgânico é um dos conceitos dados para a queimadura de mão. Esta pode ser decorrente de diversas origens de traumas, sendo os mais comuns por exposição a chamas, líquidos quentes, substâncias químicas, radiação, atrito e fricção, corrente elétrica e exposição ao frio [1,5].

\section{Classificação da gravidade da lesão}

Para a triagem e o melhor diagnóstico de um paciente queimado, é necessário que se levem em conta a extensão e a profundidade da lesão. Estes parâmetros têm como objetivo orientar as condutas clínicas e cirúrgicas subsequentes $[1,6]$.

Classificação quanto à profundidade: as queimaduras são classificadas em graus de profundidade, como descrito no Quadro 1.

Classificação quanto à extensão: a classificação da gravidade da queimadura leva em conta também a extensão (Quadro 2), que se avalia pelo método de Lund-Browder, o qual é considerado o mais preciso, especialmente em crianças, e o agente que a causou, podendo ser térmico ou elétrico. De acordo com o método de Lund-Browder, que avalia a extensão da queimadura de acordo com a área corporal acometida, cada mão representa $3 \%$ da superfície corporal, tanto em crianças quanto em adultos [1].

Quadro 1. Classificação de queimaduras em graus de profundidade e suas características mais marcantes. [1,7-9]

\begin{tabular}{|l|l|l|}
\hline \multicolumn{1}{|c|}{ Grau } & \multicolumn{1}{|c|}{ Acometimento } & \multicolumn{1}{c|}{ Características } \\
\hline Primeiro & Epiderme & $\begin{array}{l}\text { Eritematosa, dolorida, } \\
\text { seca }\end{array}$ \\
$\begin{array}{l}\text { Segundo } \\
\text { (superficial) }\end{array}$ & $\begin{array}{l}\text { Epiderme e derme } \\
\text { (até camada papilar) }\end{array}$ & $\begin{array}{l}\text { Rosada, bolhas, } \\
\text { enchimento capilar }\end{array}$ \\
$\begin{array}{l}\text { Segundo } \\
\text { (profunda) }\end{array}$ & $\begin{array}{l}\text { Epiderme e derme } \\
\text { (até camada reticular), } \\
\text { destrói terminações } \\
\text { nervosas }\end{array}$ & $\begin{array}{l}\text { Pálida, sem enchimento } \\
\text { capilar, necrose parcial }\end{array}$ \\
\hline Terceiro & $\begin{array}{l}\text { Todas as camadas da } \\
\text { epiderme e derme, } \\
\text { possível subcutânea }\end{array}$ & $\begin{array}{l}\text { Pálida a fracamente } \\
\text { escurecida, indolor, } \\
\text { necrose total ou escara } \\
\text { necrótica, sem bolhas }\end{array}$ \\
\hline
\end{tabular}

Após obter todas as informações sobre profundidade e extensão, faz-se possível uma classificação simplificada da gravidade (Quadro 2). Existem queimaduras que são consideradas graves independentemente da sua extensão, como as de terceiro grau nas mãos [1]. A idade constitui-se em fator agravante nos seus extremos, ou 
seja, nas crianças, pela maior relação entre superfície e volume corporal, e nos idosos pela maior dificuldade nas respostas fisiológicas do organismo [1,7].

Quadro 2. Classificação da gravidade de queimaduras considerando a extensão e a profundidade. [1,7-9]

\begin{tabular}{|c|c|c|c|}
\hline & Leve & Moderada & Grave \\
\hline $2^{\text {o }}$ grau & $<15 \%$ & $15 \%$ a $25 \%$ & $>25 \%$ \\
\hline 3 ograu & $<2 \%$ & $3 \%$ a $10 \%$ & $>10 \%$ \\
\hline
\end{tabular}

\section{Condutas iniciais na mão queimada}

A conduta inicial em pacientes com queimaduras em geral foi sintetizada na Figura 1. O tratamento inicial é de grande importância para uma possível recuperação bem sucedida. Existem três fatores determinantes para que isso ocorra: a profundidade da lesão, os cuidados na fase aguda e os procedimentos de reconstrução. Existem outros três fatores fisiopatológicos que acompanham a queimadura térmica e precisam ser cuidadosamente supervisionados: o edema, a inflamação e a limitação dos movimentos [1, 8-12].

A presença desses fatores acarreta uma alteração na posição da mão, denominada mão em garra, caracterizada pela adução do polegar, flexão das articulações interfalângicas proximais, hiperextensão das articulações metacarpofalângicas e flexão do punho. Se esta condição não for tratada desde o início, pode ocorrer o enrijecimento articular e formação de aderências tendinosas no membro. $\mathrm{O}$ tratamento consiste em curativos diários com agentes antibacterianos, curativos oclusivos em posição funcional, elevação do membro e exercícios diários, que servem principalmente para tratar o edema que causa as aderências [1,10-14]. As condutas locais iniciais foram sintetizadas na Figura 2.

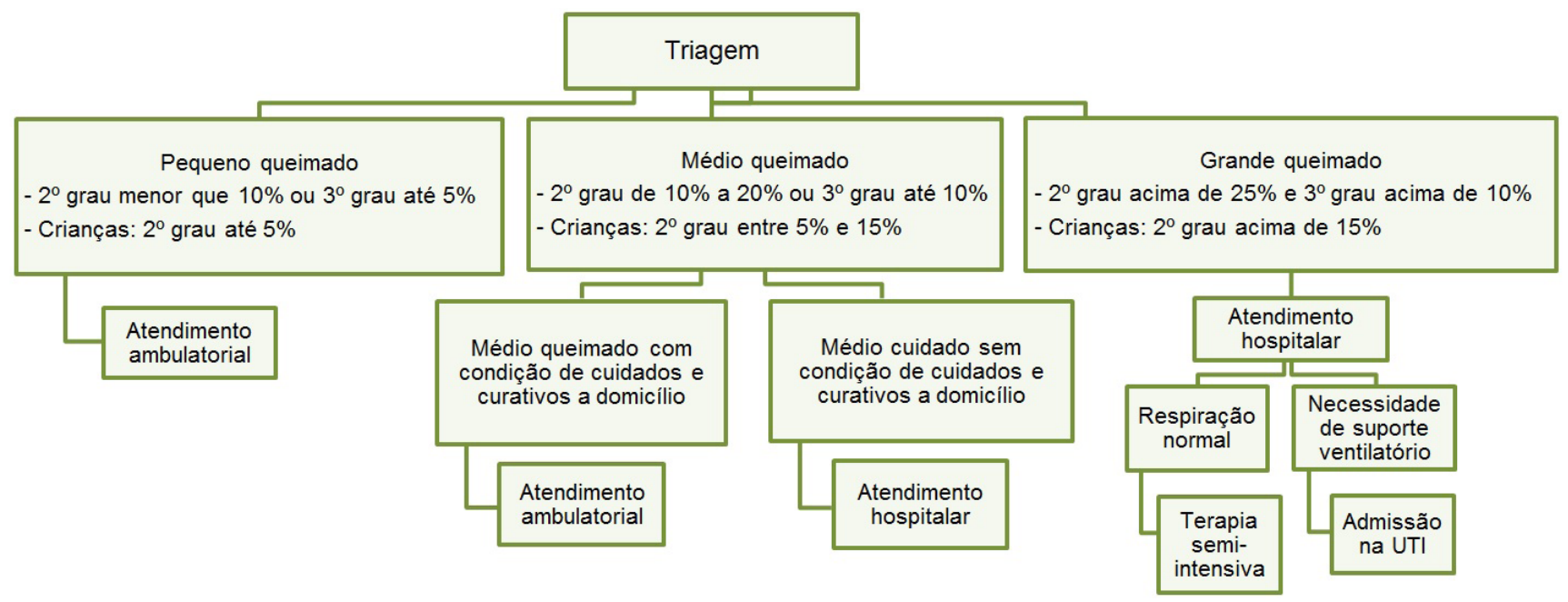

Figura 1. Fluxograma para orientação das condutas iniciais com o paciente queimado, levando em consideração o grau e a extensão da queimadura, visando direcionamento das condutas iniciais. [9-12]

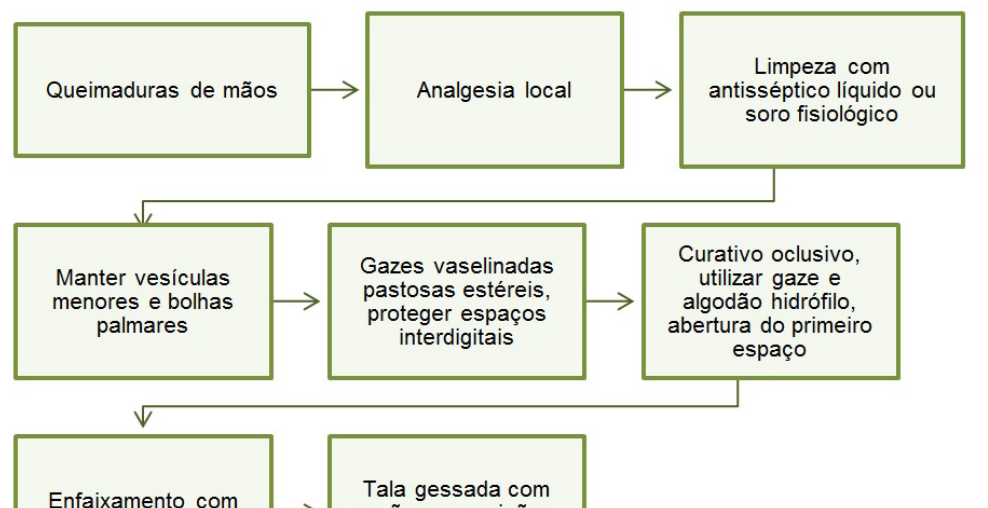

Figura 2. Fluxograma de condutas nas queimaduras de mãos. [1] 


\section{Procedimentos cirúrgicos de urgência}

\section{Escarotomia}

A escarotomia consiste na retirada do tecido desvitalizado formado após a agressão gerada pela queimadura. A pressão intersticial no interior da escara é aumentada por causa do edema e, assim sendo, pode prejudicar o fluxo sanguíneo na região. Dessa forma, a escarotomia promove uma descompressão, uma vez que a pressão no interior do compartimento vai diminuir e a perfusão do tecido aumentar após a realização do procedimento. Em todos os pacientes com queimaduras severas, aconselha-se a palpação dos pulsos radiais. Se não estiverem presentes, a circulação sanguínea para os tecidos provavelmente está inadequada devido à pressão presente nos tecidos acometidos pela queimadura. Dessa forma, uma escarotomia é indicada para evitar maiores perdas de tecido. Escarotomias são geralmente realizadas em pacientes com queimaduras circunferenciais de terceiro grau nas extremidades ou no tronco anterior. Em se tratando de escarotomias de mão, devem ser feitas quatro incisões longitudinais na porção dorsal entre os ossos metacarpais (Figura 3). Nos dedos, as incisões devem ser feitas nas laterais, tentando evitar a borda radial, dando, portanto, preferência a incisionar na borda ulnar de cada dedo. Em geral, uma incisão por dedo é suficiente. Caso esse procedimento seja realizado de forma tardia, pode haver problemas circulatórios, lesões nervosas, necrose muscular e perda funcional $[2,15,16]$.

\section{Fasciotomia}

A fasciotomia é indicada nos casos em que há diagnóstico de síndrome compartimental, que ocorre quando a pressão em um compartimento muscular excede a pressão de perfusão venosa, diminuindo o fluxo sanguíneo. Essa síndrome, se não tratada ou se tratada inadequadamente, pode levar à isquemia, tanto nervosa quanto muscular. Os primeiros sinais que podem indicar síndrome compartimental são dor fora da proporção e dor com extensão passiva dos músculos no compartimento afetado. Com a progressão dos sintomas, ocorre parestesia, indicando disfunção nervosa por isquemia, fraqueza muscular e, tardiamente, paralisia. Portanto, o objetivo da fasciotomia é a restauração da perfusão sanguínea muscular em até seis horas, através da descompressão do compartimento por abertura da fáscia. O diagnóstico tardio ou a realização de uma fasciotomia 12 horas ou mais após o início da síndrome compartimental pode levar a pouca ou nenhuma melhora funcional $[17,18]$.

\section{Abertura do túnel do carpo}

A síndrome do túnel do carpo caracteriza-se pela compressão do nervo mediano internamente à região anatômica do pulso, podendo ser causada pela diminuição do espaço nessa região ou pelo aumento do volume das estruturas ali presentes. Essa patologia apresenta-se, mais frequentemente, por predisposição congênita, porém pode ser uma sequela pós-traumática de queimadura de mão e membro superior. Mullins et al. [19], em estudo que avaliou os casos de síndrome do túnel do carpo pós queimaduras de mão, concluíram que esse quadro ocorre muito comumente e que a etiologia mais comum é a de queimaduras elétricas, com uma incidência de $56 \%$ no grupo avaliado. Todos os pacientes avaliados nesse estudo tiveram, como tratamento imediato após o diagnóstico, a descompressão cirúrgica do túnel do carpo. Portanto,

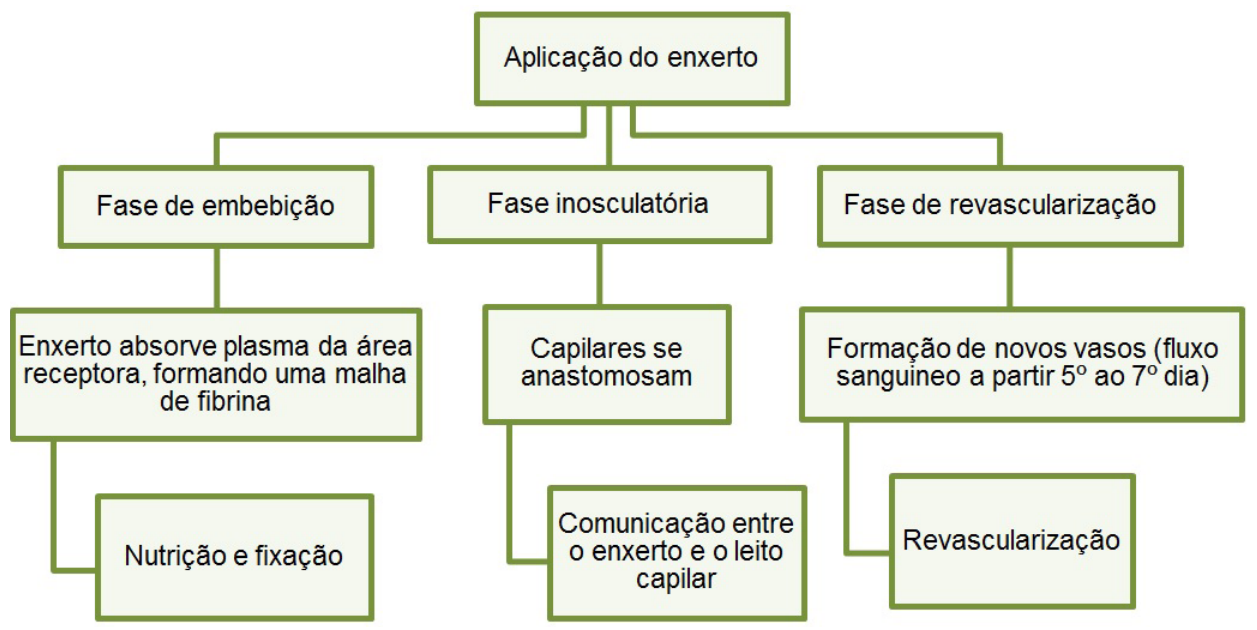

Figura 3. Fluxograma que sintetiza as fases do enxerto pós-queimaduras. [1,25] 
além das consequências diretas do trauma de queimadura sobre a mão, existe uma chance aumentada de aprisionamento dos nervos das mãos, especialmente do nervo mediano no túnel do carpo, em decorrência do edema excessivo $[1,2,19,20]$.

\section{Cuidados locais subsequentes}

\section{Curativos}

Nos curativos subsequentes, para uma melhor assepsia deve-se lavar o local da lesão suavemente com soro fisiológico antes e depois da aplicação de sabão antisséptico, o qual deve permanecer por no mínimo cinco minutos sobre o ferimento. A análise e a avaliação da dor também são importantes nessas trocas de curativo subsequentes, a fim de que seja tomada a conduta analgésica adequada, tanto farmacológica, com a utilização de lidocaína, paracetamol e opioides, quanto não farmacológica, que utiliza técnicas psicológicas de relaxamento, distração, terapia cognitivo-comportamental e até mesmo hipnose $[1,16]$.

\section{Agentes tópicos}

Agentes tópicos antimicrobianos têm importante indicação, tendo em vista que a pele lesada perde sua barreira natural, favorecendo a contaminação por bactérias locais. O produto mais utilizado é a sulfadiazina de prata a $1 \%$, visto que não provoca ardência, não induz a nenhum distúrbio eletrolítico e possui amplo espectro antibacteriano. Além disso, pode-se associar à sulfadiazina de prata o nitrato de cério a $2,2 \%$, o qual aumenta a ação antibacteriana e a resposta imunológica. A eficiência desses agentes tópicos locais requer uma troca regular dos curativos [1,21-23].

A hidroterapia associada à utilização de agentes antimicrobianos e à realização diária de curativos oclusivos por um período de três semanas permite uma boa recuperação das queimaduras, possibilitando, então, a aplicação do enxerto cutâneo conforme necessário. Por vezes, podem-se realizar leves ressecções do tecido com anestesia local e sem a aplicação de enxertia cutânea imediata, para apressar a eliminação do tecido necrótico. A gaze parafinada é um curativo que proporciona a mobilização máxima da mão, acelera a epitelização e evita a dor provocada pela aderência ao ferimento de espessura parcial superficial (aquele que acomete a epiderme e a camada superficial da derme) $[1,2]$.

\section{Desbridamento}

Nessa etapa do tratamento, as atenções são voltadas à epitelização e à cicatrização da área. Profundidade, tamanho e tempo de cicatrização da queimadura são os fatores que determinam se o desbridamento da ferida deve ser feito (Quadro 3).

As indicações para a excisão cirúrgica são queimaduras de terceiro grau, quarto grau e também as de segundo grau que atinjam a derme e que não tenham cicatrizado em duas semanas. Em se tratando de terceiro e quarto graus, logo após o paciente estar em condições estáveis e após as feridas serem bem demarcadas, é indicada a excisão. Um grande avanço no tratamento das queimaduras foi a introdução da incisão tangencial. Dessa forma, várias lâminas finas da ferida são retiradas, deixando, assim, o tecido saudável exposto para que a técnica de enxertia possa ser aplicada. Conforme o desbridamento progride em profundidade, o espaço entre os capilares torna-se mais amplo. Para determinar se o desbridamento está adequado, veias trombóticas e tecido hemorrágico sugerem incisão mais profunda. Já uma superfície úmida e brilhante indica que o desbridamento foi feito corretamente [1].

Quadro 3. Tipos de desbridamento, auxiliando na escolha da melhor conduta de acordo com as características apresentadas: profundidade, tamanho e tempo de cicatrização.

\begin{tabular}{|c|c|c|}
\hline Tipo de desbridamento & Características & Indicação \\
\hline $\begin{array}{l}\text { Desbridamento } \\
\text { conservador }\end{array}$ & $\begin{array}{l}\text { Hidroterapia, aplicação de agentes antimicrobianos tópicos, } \\
\text { realização de curativos oclusivos diários. } \\
\text { Enxertia por volta de } 3 \text { semanas após a lesão. } \\
\text { Evita a remoção de tecido viável, o qual, progressivamente, } \\
\text { pode evoluir para epitelização. }\end{array}$ & $\begin{array}{l}\text { Indicada nos casos de queimaduras mistas de } 2^{\circ} \text { grau } \\
\text { profundo e } 3^{\circ} \text { grau. }\end{array}$ \\
\hline $\begin{array}{l}\text { Desbridamento até } \\
\text { a fáscia }\end{array}$ & $\begin{array}{l}\text { O desbridamento do tecido é feito em bloco, atingindo } \\
\text { todas as camadas da pele até chegar à fáscia, onde há boa } \\
\text { vascularização. }\end{array}$ & $\begin{array}{l}\text { Indicada para o tratamento de queimaduras características } \\
\text { de } 3^{\circ} \text { grau (escara necrótica marrom e espessa). }\end{array}$ \\
\hline $\begin{array}{l}\text { Desbridamento } \\
\text { tangencial/sequencial }\end{array}$ & $\begin{array}{l}\text { A remoção do tecido desvitalizado é feita de acordo com } \\
\text { o padrão puntiforme de sangramento, tentando preservar ao } \\
\text { máximo áreas viáveis. }\end{array}$ & $\begin{array}{l}\text { Indicada em casos de queimaduras profundas onde não há } \\
\text { características de escara necrótica espessa, marrom e bem } \\
\text { definida, ou seja, onde não se sabe a profundidade da lesão. }\end{array}$ \\
\hline
\end{tabular}




\section{Tratamentos cirúrgicos}

\section{Enxertos}

Em casos de queimaduras nos quais há perda de revestimento cutâneo, faz-se necessária a enxertia cutânea após a realização de desbridamento (Quadros 4 e 5). A aplicação do enxerto deve ser realizada sobre o tecido de granulação já viável. É de imensa importância para se obter o fechamento de queimaduras de terceiro grau $[1,24,25]$.

Quadro 4. Nas queimaduras em que há perda de revestimento cutâneo, faz-se necessária a aplicação de enxerto cutâneo, podendo ser do tipo parcial ou total, de acordo com suas características. [13,23]

\begin{tabular}{|l|l|}
\hline \multicolumn{1}{|c|}{ Tipo de enxerto } & \multicolumn{1}{c|}{ Características } \\
Enxerto total & $\begin{array}{l}\text { Composto por epiderme e derme em sua } \\
\text { total espessura. } \\
\text { Utilizado em áreas menores e funcionalmente } \\
\text { mais relevantes. }\end{array}$ \\
$\begin{array}{l}\text { Composto por epiderme e apenas parte } \\
\text { da derme. } \\
\text { Utilizado em ferimentos mais extensos. }\end{array}$ \\
\hline
\end{tabular}

Quadro 5. Classificação da complexidade do enxerto. [13,23]

\begin{tabular}{|l|l|}
\hline Simples & Complexidade do enxerto \\
Composto & $\begin{array}{l}\text { Compreende apenas derme e Epiderme } \\
\text { Contém, além de derme e Epiderme, um } \\
\text { adicional ou de gordura ou de cartilagem }\end{array}$ \\
\hline
\end{tabular}

A enxertia cutânea consiste na transferência de tecido viável de uma determinada área do corpo para a área acometida pela queimadura. Quando se utiliza a transferência de pele do próprio paciente, denomina-se autoenxerto. Pode-se ainda retirar o enxerto de outra pessoa, consistindo nos homoenxertos, ou ainda retirar enxertos de indivíduos de outras espécies, consistindo em heteroenxertos. Esta última modalidade de enxerto funciona apenas como um curativo biológico, sendo utilizada de forma transitória, não permanecendo no receptor. Em se tratando de membros superiores, priorizam-se enxertos cutâneos espessos, ou seja, que carregam mais derme, possibilitando menor retração do tecido, maior proteção local e melhor recuperação funcional da área acometida [1].

Um estudo clínico randomizado com 40 pacientes que apresentavam queimaduras de mãos concluiu que houve melhores resultados funcionais nas mãos e menor tempo de internação hospitalar no grupo que realizou excisão precoce e enxertia subsequente, comparativamente ao grupo que realizou enxertia tardia [24]. No entanto, na literatura existem controvérsias quanto ao período em que a enxertia cutânea deve ser realizada. Alguns autores defendem um tratamento mais conservador, com enxertia somente após o tratamento inicial, enquanto outros acreditam que quanto mais rapidamente o tecido necrótico for removido e, concomitantemente, o enxerto for aplicado, melhor e mais rápida será a recuperação da pele do paciente $[1,24,25]$. Além disso, em se tratando de mão, deve-se tentar ao máximo a preservação do plexo venoso dorsal da mesma, visando a preservar a drenagem venosa [1].

\section{Fases do enxerto}

$\mathrm{O}$ processo de integração do enxerto e suas respectivas fases é descrito na Figura 3. Após a integração do enxerto ao seu leito receptor, proteínas contráteis e miofibroblastos encarregam-se de promover a contração do mesmo. O processo de contração é lento e pode ter duração de até seis meses. São relatadas diferenças de contração conforme o tipo de enxerto aplicado (total ou parcial), sendo o enxerto total o de maior contração $[1,25]$.

\section{DISCUSSÃO}

O objetivo em qualquer queimadura de extremidade é prover ao paciente, através de uma equipe multidisciplinar, a recuperação do aspecto funcional, útil, da área acometida. Dessa forma, é muito importante que a equipe tenha conhecimento da fisiopatologia, das classificações e do tratamento cirúrgico, bem como das últimas atualizações em relação ao tratamento de queimaduras. Para atingir este objetivo, é importante a rapidez na triagem do paciente, avaliando o grau e a extensão do ferimento e, assim, direcionando o paciente ao tratamento adequado. A triagem correta e a rapidez na aplicação do tratamento são essenciais no prognóstico do paciente queimado. O manejo da queimadura nas primeiras 24 horas foi referido como um dos maiores desafios no tratamento de queimaduras, tendo relação direta com a morbidade e com a mortalidade do paciente. [26,27]

Existem diferenças entre os artigos em relação à taxa de incidência das queimaduras de mãos na população, embora todos os valores sejam expressivos (acima de 70\%). A alta incidência torna mais crucial que o tratamento das queimaduras de mãos seja feito de forma rápida e eficiente, pois representa um problema de saúde pública. É importante identificar as alterações envolvidas e os possíveis saldos negativos decorrentes do trauma de mão. Sugere-se que durante o 
acompanhamento do paciente pós-queimadura de mão, especialmente após queimaduras térmicas, a equipe considere o desenvolvimento da síndrome do túnel do carpo, um dos possíveis e comuns saldos negativos das queimaduras de mão.

Inicialmente, o cerne da preocupação deve ser a sobrevida e a reabilitação do paciente. Posteriormente, caso haja sequelas, estas devem ser tratadas. Visto que deformidades das mãos são sequelas comuns de queimaduras, deve-se ressaltar a importância da preocupação constante em manter a mão do paciente em posição adequada do início ao fim do tratamento, possibilitando melhor prognóstico funcional e estético. Caso o tratamento da mão queimada não seja feito corretamente, é comum a ocorrência de contraturas pós-queimaduras, as quais constituem um problema grave e são difíceis de resolver. Outro tipo de sequela relatada pela literatura, a sindactilia pós queimadura, é uma sequela grave e incapacitante, passível de limitar a função preensora da mão. É decorrente de má orientação na cicatrização na fase aguda da queimadura. A sindactilia, porém, pode ser corrigida por cirurgia reparadora, restaurando, na grande maioria dos casos, a função da mão [28-30].

Nem todas as queimaduras de mão requerem tratamento cirúrgico. Todavia, o reconhecimento oportuno da necessidade de uma intervenção cirúrgica é crucial para atingir bons resultados funcionais para o membro. Mohammadi et al. [24] concluíram, através de um estudo randomizado incluindo 50 pacientes, que embora as excisões prematuras seguidas de enxerto cutâneo tenham reduzido o tempo de internação e acelerado o tratamento, não demostraram vantagens nos quesitos recuperação do aspecto funcional, cicatrização e satisfação estética. Logo, de acordo com esses autores, compete ao cirurgião decidir pelo tratamento inicial com excisão e enxertia ou tratamento inicial mais conservador, com enxertia somente após um período de recuperação do paciente [24]. Entretanto, Vaitsman et al. [25] defendem que, nos casos de queimaduras de mão, a excisão precoce, antes de haver colonização bacteriana, não só previne infecções, como diminui a incidência de cicatrizes, de sequelas pós-operatórias incapacitantes e inestéticas e de cirurgias reparadoras [25].

Considerando que as queimaduras correspondem à grande parte dos traumas em emergências e considerando a importância da recuperação funcional das mãos, o tema de queimaduras de mão temse apresentado muito pouco no cenário cientifico, causando uma estagnação em descobertas de melhores tratamentos, carecendo, portanto, de mais pesquisas e inovações.

\section{COMENTÁRIOS FINAIS}

A abordagem prévia da queimadura de mão poderá evitar sequelas irreversíveis nesse membro. $\mathrm{O}$ manejo adequado na queimadura de mão inclui desde a avaliação clinica inicial da área queimada por um médico generalista à realização de condutas precoces com o objetivo de evitar a perda de função do membro e futuras reconstruções desnecessárias. A elevada incidência desse tipo de queimadura, nos últimos tempos, também aumenta a relevância de uma conduta adequada.

\section{REFERÊNCIAS}

1. Pardini A, Freitas A. Cirurgia da Mão: Lesões não-traumáticas. 2 ed. Rio de Janeiro: Medbook; 2008.

2. Kamolz LP, Kitzinger HB, Karle B, Frey M. The treatment of hand burns. Burns. 2009;35(3):327-37. http://dx.doi.org/10.1016/j. burns.2008.08.004

3. Mckee DM. Acute management of burn injuries to the hand and upper extremity. J Hand Surg Am. 2010; 35A:1542-4. http://dx.doi. org/10.1016/j.jhsa.2010.03.019

4. Richards WT, Vergara E, Dalaly DG, Coady-Fariborzian L, Mozingo DW. Acute surgical management of hand burns. J Hand Surg Am. 2014;39(10):2075-85.e2. http://dx.doi.org/10.1016/j.jhsa.2014.07.032

5. Narikawa R, Michelski DA, Hiraki PY, Ueda T, Nakamoto HA, Junior PT, Ferreira MC. Análise epidemiológica da mão queimada no Hospital das Clínicas da Faculdade de Medicina da Universidade de São Paulo. Rev Bras Queimaduras. 2011;10(3):89-92.

6. Duffy BJ, McLaughlin PM, Eichelberger MR. Assessment, triage, and early management of burns in children. Clin Pediatr Emerg Med. 2006;7(2):82-93. http://dx.doi.org/10.1016/j.cpem.2006.04.001

7. Evers LH, Bhavsar D, Mailänder P. The biology of burn injury. Exp Dermatol. 2010;19(9):777-83. http://dx.doi.org/10.1111/j.16000625.2010.01105.x

8. Llooyd ECO, Rodgers BC, Michener M, Williams MS. Outpatient Burns: Prevention and Care. Am Fam Physician. 2012;85(1):25-32

9. Alharbi Z, Piatkowski A, Dembinski R, Reckort S, Grieb G, Kauczok J, Pallua N. Treatment of burns in the first 24 hours: simple and practical guide by answering 10 questions in a step-by-step form. World J Emerg Surg. 2012;7(1):13. http://dx.doi.org/10.1186/17497922-7-13 
10. Grunwald TB, Garner WL. Acute Burns. Plast Reconstr Surg. 2008;121(5):311e-319e. http://dx.doi.org/10.1097/PRS.0b013e318172ae1f

11. Júnior JBG, Moscozo MVA, Filho ALL, Menezes CMGG, Tavares FMO, Oliveira GM, Júnior WNG. Tratamento de pacientes queimados internados em Hospital Geral. Rev Soc Bras Cir Plást. 2007;22(4):228-32.

12. Jenkins JA, Schraga ED. Emergent Management of Thermal Burns. EUA; 2014 [Updated 2014 Feb; cited March 2015]. Available from: http://emedicine.medscape.com/article/769193-overview\#showall

13. Fufa DT, Chuang SS, Yang JY. Postburn contractures of the hand. J Hand Surg Am. 2014;39(9):1869-76. http://dx.doi.org/10.1016/j. jhsa.2014.03.018

14. Pan BS, Vu AT, Yakuboff KP. Management of the acutely burned hand. J Hand Surg Am. 2015; 40 (7):1477-84. http://dx.doi.org/10.1016/j. jhsa.2015.02.033

15. Piccolo NS, Piccolo MS, Piccolo PD, Piccolo-Daher R, Piccolo ND, Piccolo MT. Escharotomies, fasciotomies and carpal tunnel release in burn patients - review of the literature and presentation of an algorithm for surgical decision making. Handchir Mikrochir Plast Chir. 2007;39(3):161-7. http://dx.doi.org/10.1055/s-2007-965322

16. Castro RJA, Leal PC, Sakata RK. Tratamento da dor em queimaduras. Rev Bras Anestesiol. 2013;63(1):149-58. http://dx.doi.org/10.1590/ S0034-70942013000100013

17. Junior ATR. Acute compartment syndrome. Washington; 2015 [Updated 2015 Feb; cited 2015 March 14]. Available from: http://emedicine. medscape.com/article/307668-overview

18. Stracciolini A, Hammerberg EM. Acute compartment syndrome of the extremities. 2014 [updated 2014 Jul; cited 2015 March 14]. Available from: http://www.uptodate.com/contents/acute-compartment-syndrome-of-the-extremities

19. Mullins RF, Alam B, Mian MAH. Carpal Tunnel Syndrome following burns. Ann Burns Fire Disasters. 2008;21(3):153-5.

20. Bolgiani AN, Serra MCVF. Atualização no tratamento local das queimaduras. Rev Bras Queimaduras. 2010;9(2):38-44.

21. Filho JAL, Dadalti P, Souza DC, Souza PRC, Silva MAL, Takiya CM. Enxertia de pele em oncologia cutânea. An Bras Dermatol. 2006;81(5):465-72. http://dx.doi.org/10.1590/S0365-05962006000500010

22. Henrique DM, Silva LD, Costa ACR, Rezende APMB, Santos JAS, Menezes MM, Maurer TC. Controle de infecção no centro de tratamento de queimados: revisão de literatura. Rev Bras Queimaduras. 2013;12(4):230-4.

23. Pan BS, Vu AT, Yakuboff KP. Management of the Acutely Burned Hand. J Hand Surg Am. 2015;40(7):1477-84. http://dx.doi.org/10.1016/j. jhsa.2015.02.033

24. Mohammadi AA, Bakhshaeekia AR, Marzban S, Abbasi S, Ashraf AR, Mohammadi MK, Toulide-Ie HR, Tavakkolian AR. Early excision and skin grafting versus delayed skin grafting in deep hand burns (a randomised clinical controlled trial). Burns. 2011;37(1):36-41. http:// dx.doi.org/10.1016/j.burns.2010.02.005

25. Vaitsman GP, Guimarães VG, Freire RF, Esbérard F, Filho FV, Silva MAL. Excisão precoce e autoenxertia cutânea em queimadura de mãos. Rev Bras Cir Plást. 2010;25(3):94.

26. Yast AC, Şenel E, Saydam M, Özok G, Çoruh A, Yorganc1 K. Guideline and treatment algorithm for burn injuries. Ulus Travma Acil Cerrahi Derg. 2015;21(2):79-89. http://dx.doi.org/10.5505/tjtes.2015.88261

27. Daigeler A, Kapalschinski N, Lehnhardt M. Therapy of burns. Der Chirurg. 2015;86(4):389-401. http://dx.doi.org/10.1007/s00104-014 2919-3

28. Cowan AC, Stegink-Jansen WC. Rehabilitation of hand burn injuries: Current updates. Injury. 2013;44(3):391-6. http://dx.doi.org/10.1016/j. injury.2013.01.015

29. Bhattacharya S. Avoiding unfavorable results in postburn contracture hand. Indian J Plast Surg. 2013;46(2):434-44. http://dx.doi org/10.4103/0970-0358.118625

30. Ribeiro LMB, de Morais VS, Fachinelli, FA. Sindactilia pós-queimadura da mão. Rev Bras Cir Plást. 2013;28(1):130-2. http://dx.doi org/10.1590/S1983-51752013000100022 